\title{
Phylogenetic Diversity Analysis of Ralstonia solanacearum, Pseudomonas fluorescens and Trichoderma asperellum Isolated from Tomato Rhizosphere Soil in Karnataka
}

\author{
K. Soumya ${ }^{1 *}$, K. Narasimha Murthy ${ }^{3}$, C. Srinivas ${ }^{2}$ and S.R. Niranjana ${ }^{2}$ \\ ${ }^{1}$ Department of Microbiology, Field Marshal K. M. Cariappa College, A Constituent College \\ of Mangalore University, Madikeri - 571201, Karnataka, India \\ ${ }^{2}$ Department of Studies in Biotechnology, University of Mysore, Manasagangotri, \\ Mysore -570 006, Karnataka, India \\ ${ }^{3}$ Department of Microbiology and Biotechnology, Jnanabharathi Campus, Bangalore \\ University, Bangalore- 560 056, India \\ *Corresponding author
}

\section{Ke y w o r d s \\ Molecular identification, phylogenetic tree, PCR amplification, $R$. solanacearum, $P$. fluorescens, T. asperellum \\ Article Info \\ Accepted: 04 February 2019 Available Online: 10 March 2019}

\section{A B S T R A C T}

Phylogenetic implication in bacterial genomics is important to understanding difficulties such as population history, antimicrobial resistance and transmission dynamics. It has been claimed that partial genome sequences would clarify phylogenetic relationships between isolated organisms, but up to now, no sustaining approach has been proposed to use competently these data. concatenation of sequences of different genes as well as building of consensus trees only consider the few genes that are shared among all organisms. The phylogenetic has been plagued by an apparent state of contradiction since the distorting effects of recombination on phylogeny were discovered more than a decade ago. Total of 100 isolates were isolated wilted tomato plant and rhizosphere soil, amongst ten highly virulent isolates were selected based on morphological, biochemical characteristics and pathogenicity studies, as well as 16S rRNA gene sequencing. The rhizosphere soil samples of healthy tomato plants were used to isolate $T$. asperellum and $P$. fluorescens were identified based on morphological and molecular characterization. Total of fifteen isolates among them, ten isolates of $R$. solanacearum, three isolates of Pseudomonas fluorescens and two isolates of Trichoderma asperellum were isolated from soil samples collected from different locations in Karnataka. The present work demonstrates for the identification of $R$. solanacearum, $P$. fluorescens and $T$. asperellum based on molecular methods based on 16S rRNA sequencing and NCBI BLAST search was performed, multiple sequences alignment and phylogenetic trees were constructed using CLUSTAL X2 2.1 (Windows version). The sequences were deposited to NCBI database. 


\section{Introduction}

A phylogenetic tree is a branching diagram or "tree" showing the inferred evolutionary relationships among various biological species or other entities their phylogeny based upon resemblances and dissimilarities in their physical or genetic characteristics. More than 3000 bacterial have been sequenced and deposited in public databases to date, including the results of a large scale effort to choose organisms for genome sequencing based on their phylogenetic diversity ( $\mathrm{Wu}$ et al., 2009). In this method, a tree is assembled by seeing the phenotypic resemblances of the species without trying to understand the evolutionary pathways of the species. Since a tree assembled by this method does not essentially reflect evolutionary relationships but somewhat is designed to signify phenotypic similarity, trees assembled via this technique are called phenograms. A phylogenetic tree based on such information is often named a dendrogram (a branching order that may or may not be the correct phylogeny).

Phylogenetic analysis has been to determine the diversity of strains rapidly and to a degree of accurateness. Traditionally, phylogenies were incidental and taxonomy established based on studies of morphology. Recently molecular phylogenetics has been used to allow better elucidation of the evolutionary connection of the species by analyzing their DNA/protein sequences, for example their ribosomal DNA. The phylogenetic relationships among numerous of the sequenced genomes are unclear. When new species are described, it is commonplace to use a phylogeny of the gene for the small subunit ribosomal RNA to place them in a phylogenetic context. Within the past few years, many studies have been reported using DNA sequence-based phylogenetic analyses to determine the diversity of $R$. solanacearum, $P$. fluorescens and T. asperellum strains (Villa et al., 2005).

Characterization of microbial species using classical methods is not as exact as the genotyping methods. Genotypic techniques involve the amplification of a phylogenetically informative target, such as the small subunits (18S) rRNA gene and 16S rRNA are necessary for the survival of all cells and the genes encoding the rRNA are highly conserved in the fungi and bacteria respectively. The sequences of rRNA and proteins comprising the ribosome are extremely conserved during evolution as they require complex inter and intra molecular interactions to maintain the protein synthesis (Sacchi et al., 2002; Woese et al., 1977).

The 16S rRNA gene is a valued tool for this determination because its sequence has regions of both low and high conservation and since there are now hundreds of thousands of sequences available from both cultured and environmental organisms. However, it is likely that there will be differences between a phylogenetic trees inferred using the $16 \mathrm{~S}$ rRNA gene versus other phylogenetic marker genes (Eisen, 1995). Ribosomal RNA is often considered the best tool to infer prokaryotic phylogeny because it is supposed to be one of the best constrained and ubiquitous molecules available, and thus the most informative. However, several examples of likely lateral transfers concern molecules that are constrained and ubiquitous (Brown et al., 2001).

This is generally the case when linking phylogenies reconstructed from different genes, since they may have diverse amounts of phylogenetic signal, evolutionary histories or rates of evolution, and because issues like convergence, long-branch attraction, and hidden paralogy can lead to incorrect tree inference (Maddison, 1997). The aim of this to 
study the phylogenetic technique to examine the diversity of selected bacterial and fungal species in rhizosphere soil samples of tomato.

\section{Materials and Methods}

\section{Isolation and identification of $R$. Solanacearum and P. fluorescens}

Virulent strains of $R$. solanacearum were isolated from wilted tomato plants, identified by morphological biochemical and molecular characteristics and whose pathogenicity on tomato plants had been confirmed in previous work was used in this study. $R$. solanacearum was isolated on Triphenyl tetrazolium chloride (TZC) medium (Narasimha Murthy et al., 2012) P. fluorescens were isolated from rhizosphere soil of tomato fields and carried out by serial dilution technique using King's B medium (King et al., 1954). The colonies were examined for morphological characteristics such as shape, size, structure and pigmentation. Presence of fluorescence in UV light was used to select putative $P$. fluorescens colonies.

\section{Molecular Identification of $\boldsymbol{R}$.} Solanacearum and P. fluorescens

Pure culture of ten isolates of $R$. solanacearum, three isolates of Pseudomonas fluorescens were used to molecular identification.

\section{Extraction of genomic DNA from $R$ solanacearum and $P$. fluorescens}

Both Bacterial cultures $(1.5 \mathrm{ml})$ were centrifuged at $8000 \mathrm{rpm}$ for $5 \mathrm{~min}$ and supernatant was discarded. The pellet was resuspended in $600 \mu \mathrm{l}$ of TE buffer and vortexed for $1 \mathrm{~min}$. To this, $30 \mu \mathrm{l}$ of $10 \%$ SDS and $3 \mu \mathrm{lo}$ f a $20 \mathrm{mg} / \mathrm{ml}$ solution of proteinase $\mathrm{K}$ are added, mixed and incubated for 1 hour at $37^{\circ} \mathrm{C}$. After incubation, $100 \mu \mathrm{l}$ of $5 \mathrm{M} \mathrm{NaC} 1$ is added and mixed, followed by the addition of $80 \mu 1$ of $\mathrm{aCTAB} / \mathrm{NaC} 1$ solution $(0.7 \mathrm{M} \mathrm{NaC} 1$, $10 \%$ CTAB). This solution was incubated at $65^{\circ} \mathrm{C}$ for $10 \mathrm{~min}$. following incubation, an equal volume of chloroform: isoamylalcohol (24:1) was added and mixed. Centrifugation for 5 min was carried out and the aqueous layer avoiding the interface was transferred to a new tube. To this, equal volume of PCI (Phenol: Chloroform: Isoamyl alcohol) solution was added and mixed well. The tubes were then centrifuged at 14,000 rpm for $5 \mathrm{~min}$ and the supernatant was transferred to a new tube. The first extraction with chloroform: isoamyl alcohol alone was repeated again and to these 0.6 volumes of isopropanol was added and mixed gently to completely precipitate the DNA. The tubes are then centrifuged and isopropanol was decanted. The DNA pellets were then washed with $70 \%$ ethanol for three times and dried at room temperature. The DNA was then resuspended in $50-100 \mu$ of TE buffer and stored at $4^{\circ} \mathrm{C}$.

\section{Quantification of DNA with absorption}

The reliable amounts of DNA to fingerprint assays were obtained by further dilution of DNA concentration in TE buffer $\mathrm{pH} 7.6$ at 1:7 (v/v) and measuring the absorbance at $260 \mathrm{~nm}$ and $280 \mathrm{~nm}$ wave lengths in a spectrophotometer. The purity of the DNA was checked by Gel Electrophoresis with $1 \%$ Agarose in TBE Buffer (Ausubel et al., 1997).

\section{PCR amplification}

The genomic DNA of $R$. solanacearum isolates were PCR amplified usinguniversal primers; $\quad$ Forward primer 8F (AGAGTTTGATCCTGGCTCAG) and Reverse Primer 806R (GGACTACCA GGGTATCTAAT) corresponding to 16SrRNA (Seal et al., 1993). Master mixture was prepared with PCR reagents and distributed into $200 \mu 1$ PCR tubes. The reaction 
volume of $50 \mu \mathrm{l} /$ reaction was maintained which comprised of $1 \mu$ lof each primers (20pmol Concentration), $5 \mu \mathrm{l}$ of $10 \mathrm{X}$ PCR buffer, a mixture of dNTP's each at a concentration of $200 \mathrm{mM}(1 \mu \mathrm{l})$, sterile double distilled water $(40.75 \mu \mathrm{l}), 2.5 \mathrm{U}$ of Taq polymerase $(0.25 \mu \mathrm{l})$ and template DNA $(1 \mu \mathrm{l})$. Reaction mixture without the Template DNA was maintained as negative control to check contamination. Amplification reaction was performed in thermal cycler (Eppendorf A.G Barkhausenweg, Germany) for 35 cycles. The purity of the PCR product was checked by Electophoresis with $2 \%$ agarose in TBE Buffer.

\begin{tabular}{|l|l|l|}
\hline Reactions & $\begin{array}{l}\text { Temperature \& } \\
\text { Incubation Time }\end{array}$ & Cycles \\
\hline $\begin{array}{l}\text { Initial } \\
\text { Denaturation }\end{array}$ & $94^{\circ} \mathrm{C}$ for $4 \mathrm{~min}$ & \\
\hline Denaturation & $94^{\circ} \mathrm{C}$ for $40 \mathrm{~s}$ & $\begin{array}{l}35 \\
\text { cycles }\end{array}$ \\
\hline Annealing & $53^{\circ} \mathrm{C}$ for $1 \mathrm{~min}$ & \\
\hline Extension & $72^{\circ} \mathrm{C}$ for $1 \mathrm{~min}$ & \\
\hline $\begin{array}{l}\text { Final } \\
\text { extension }\end{array}$ & $72^{\circ} \mathrm{C}$ for $10 \mathrm{~min}$ & \\
\hline
\end{tabular}

\section{Isolation and identification of T. asperellum}

Rhizosphere soil samples of healthy tomato plants were collected and isolated using the soil dilution plate method on potato dextrose agar (PDA) medium. Morphological and microscopic examination in slide culture the shape, size, arrangement and development of conidiophores or phialides provided identification of $T$. asperellum. The Two $T$. asperellum isolates were sent to National Fungal Culture Collection of India (NFCCI), Agharkar Research Institute, Pune and further characterized by molecular identification based on the ITS region sequencing.

\section{Molecular identification of T. asperellum}

DNA extraction and PCR amplification from $T$. asperellum

Trichoderma asperellum were cultivated in flasks containing malt extract broth, at $26^{\circ} \mathrm{C}$ and $170 \mathrm{rpm}$. The culture was centrifuged and the pellets were washed with TE Buffer (1 M Tris- $\mathrm{HCl}, 0.5 \mathrm{M}$ EDTA $\mathrm{pH} 8.0), 500 \mu \mathrm{l}$ of lysis buffer and $10 \mu \mathrm{l}$ of $10 \%$ SDS were added. This mixture was maintained for 10 minutes at room temperature and then at $60^{\circ} \mathrm{C}$ for 10 minutes. Phenol: chloroform: Isoamyl alcohol $(250 \mu \mathrm{l})$ was added in the ratio of 25:24:1 homogenized and centrifuged at $13000 \mathrm{rpm}$. One milliliter of ethanol was added to the supernatant and centrifuged. DNA was precipitated using $1 \mathrm{ml}$ of $80 \%$ ethanol and centrifuged at $13000 \mathrm{rpm}$. Ethanol was completely dried at $40^{\circ} \mathrm{C}$. The extracted DNA was resuspended in $30 \mu 1$ of deionized water and stored at $4^{\circ} \mathrm{C}$.

\section{PCR amplification}

The PCR reactions were carried out using ITS1-F (5-CTT GGT CAT TTA GAG GAA GTA A-3) as forward primer and ITS-4 (5TCC TCC GCT TAT TGA TAT GC-3) as reverse primer respectively. The ITS regions of the rDNA repeat from the 3'end of the $18 \mathrm{~s}$ 
and the 5 'end of the 28 s gene were amplified using the two primers, ITS A and D which were synthesized on the basis of conserved regions of the eukaryotic rRNA gene (White et al., 1990).

The Thermocycler programme included following steps, Initial denaturation $\left(94{ }^{\circ} \mathrm{C}\right.$ for $4 \mathrm{~min}$ ), 30 cycles of repeated denaturation (94 ${ }^{\circ} \mathrm{C}$ for $1 \mathrm{~min}$ ), annealing $\left(40{ }^{\circ} \mathrm{C}\right.$-increasing 0.5 ${ }^{\circ} \mathrm{C}$ per second during 30s) and extension (72 ${ }^{\circ} \mathrm{C}$ for $1 \mathrm{~min}$ ) (Anderson and Cairney, 2004).

\section{Phylogenetic analysis}

The PCR products were sequenced by Sanger dideoxy method by genome bio technologies, Pune. Nucleotide BLAST was performed to all the ten obtained sequences in NCBI using blastn suite and top ten hit sequences with more than $99 \%$ similarity to the query sequences were selected for further phylogenetic analysis. Multiple sequence alignments of all these sequences were performed by using CLUSTAL-X software version 2.1. Phylogenetic tree was constructed using the same software and the alignment data was analyzed by neighbor-joining (NJ) method. The sequences were deposited in NCBI GenBank. Nucleotides BLAST search was performed at the NCBI GenBank library (Altschul et al., 1997) and compared with each other using the CLUSTALW.

The rRNA amplicons were sequenced, aligned using the Bio Edit Sequence Alignment Editor to obtain the consensus sequence, and compared to each other using CLUSTALW. The sequences were deposited in the GenBank database.

Phylogenetic tree was constructed using the same software and the alignment data was analyzed by neighbor-joining (NJ) method. The sequences were deposited in NCBI GenBank.

\section{Results and Discussion}

Molecular confirmation of $\boldsymbol{R}$. solanacearum by $16 \mathrm{~S}$ ribosomal RNA

The identification of the $R$. solanacearum isolates was confirmed by molecular analysis. The BLAST analysis of the sequences showed $98 \%$ to $99 \%$ identity to several isolates of $R$. solanacearum strains. Among 100 isolates, ten highly virulent strains were characterized and were identified as $R$. solanacearum RS1, RS2, RS3, RS4, RS5 RS6, RS7, RS8, RS9 and RS10 with Gen bank Accession numbers KF924739, KF924740, KF924741, KF924742, KF924743, KF924744, KF924745, KF924746, KF924747and KF924748 respectively (Figure 1).

\section{Molecular confirmation of Pseudomonas fluorescens by $16 \mathrm{~S}$ ribosomal RNA}

The identification rhizobacterial isolates were subjected for molecular identification. The $16 \mathrm{~S}$ ribosomal RNA gene was sequenced and aligned using the BLAST algorithm. The sequence showed $98 \%$ to $99 \%$ similarity with several isolates of $P$. fluorescens. All three isolates (Pf3, Pf5, Pf8) were identified as $P$. fluorescens (Accession Numbers: KF679344, KF679345 and KF679346). Phylogenetic relationships of $P$. fluorescens isolates inferred by neighbor-Joining (NJ) bootstrap tree analysis of $16 \mathrm{~s}$ rRNA sequences. Sequences used for this comparison were obtained from GenBank (Figure 2).

\section{Molecular identification of $T$. asperellum by ITS sequencing}

The amplified PCR nucleotides of $T$. asperellum were sequenced and a phylogenetic tree was constructed. BLAST search of the ITS sequence and multiple alignment of sequences showed $98 \%$ similarity with Trichoderma strains which 
confirms T4 and T8 as T. asperellum (Figure 3). The sequences were deposited in NCBI GenBank, with Accession Numbers: (T4): KF679342 and (T8): KF679343. The greater number of samples would have to be analyzed to statistically determine that PCR is a significantly more sensitive technique for the detection of bacterial and fungal in soil samples than culture analysis. Molecular phylogeny approaches allow, from a given set of aligned sequences, the suggestion of phylogenetic trees (inferred trees) which aim at reconstructing the past of consecutive deviation which took place during the evolution, amongst the measured sequences and their common ancestor.

Fig.1 Phylogenetic relationships of $R$. solanacearum isolates inferred by neighbor-Joining (NJ) bootstrap tree analysis of 16s rRNA sequences. Sequences used for this comparison was obtained

\section{from GenBank}

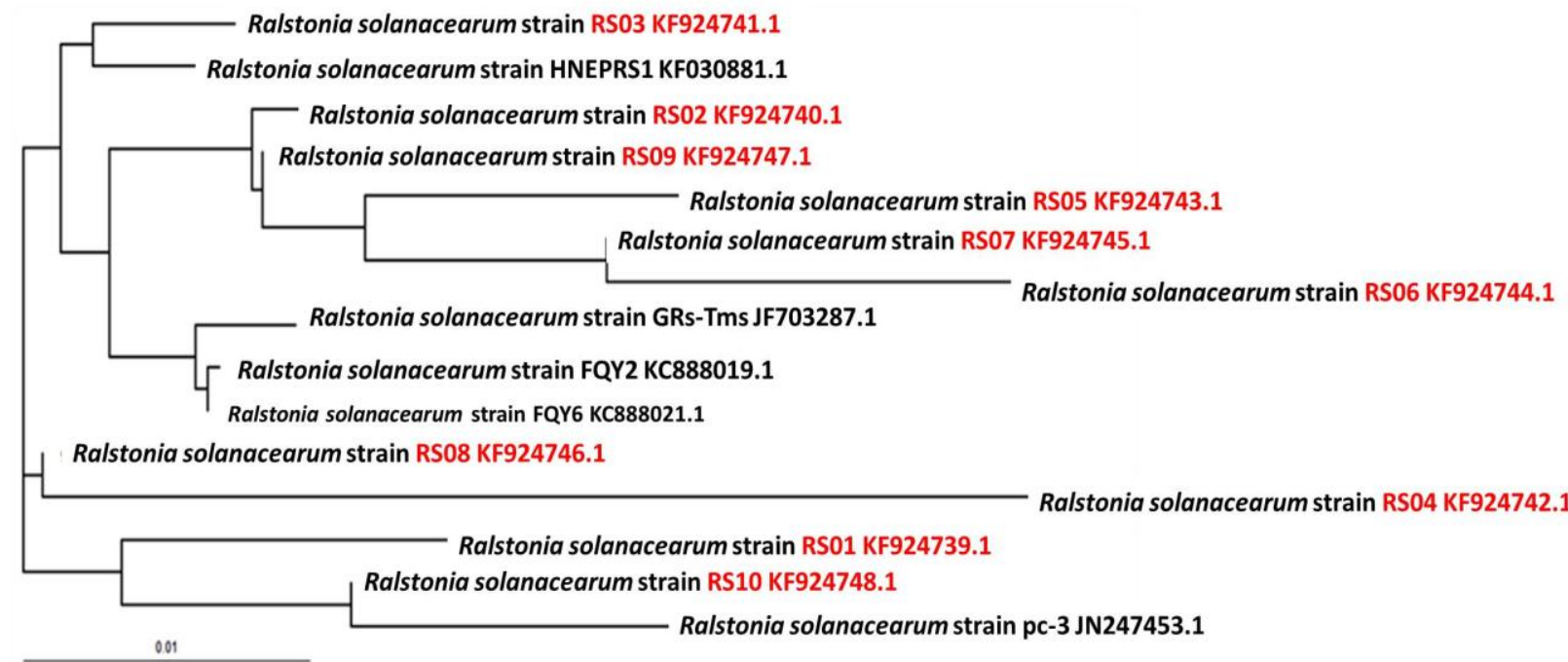

Fig.2 Phylogenetic relationships of P. fluorescens (Pf3, Pf5 and Pf8) isolates inferred by neighbor-Joining (NJ) bootstrap tree analysis of 16s rRNA sequences. Sequences used for this comparison was obtained from GenBank

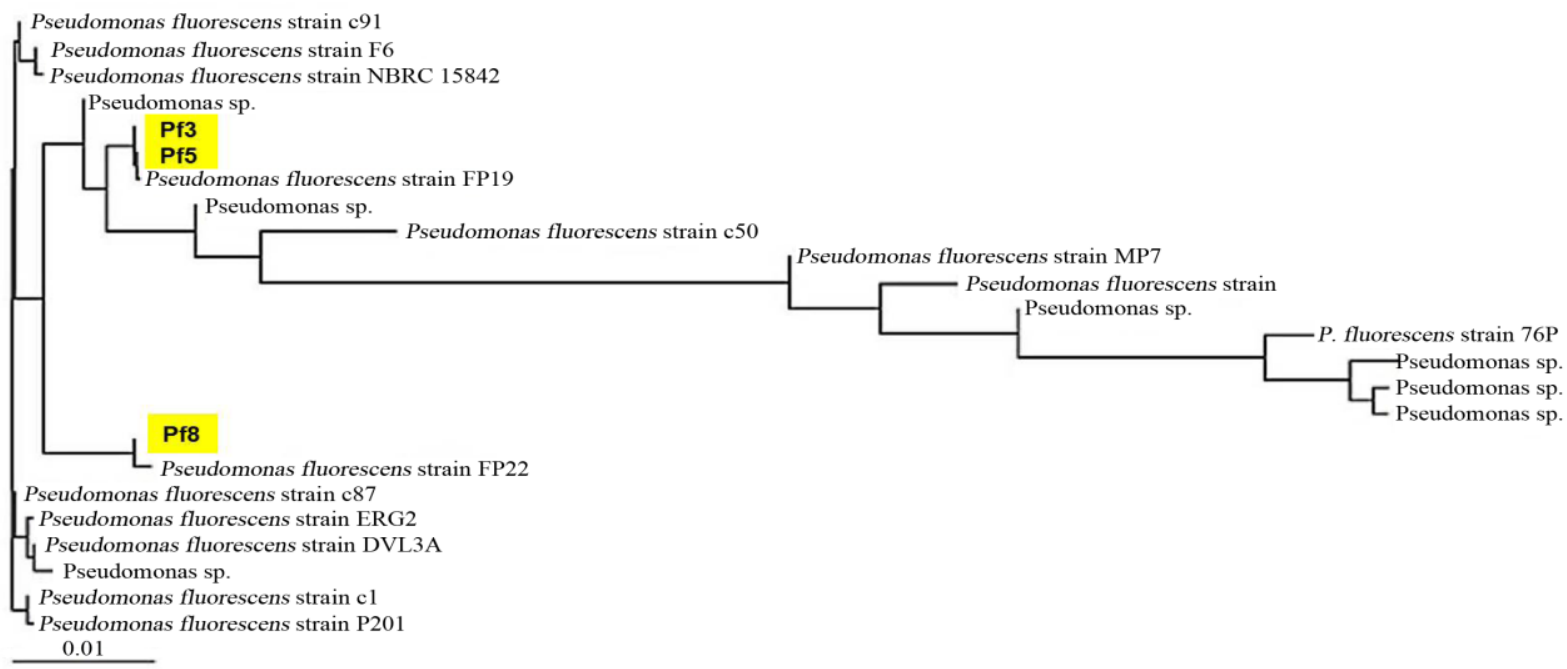


Fig.3 Phylogenetic relationships of Trichoderma asperellum (T4 and T8) isolates inferred by Neighbor-Joining (NJ) bootstrap tree analysis of ITS sequences. Sequences used for this comparison was obtained from GenBank

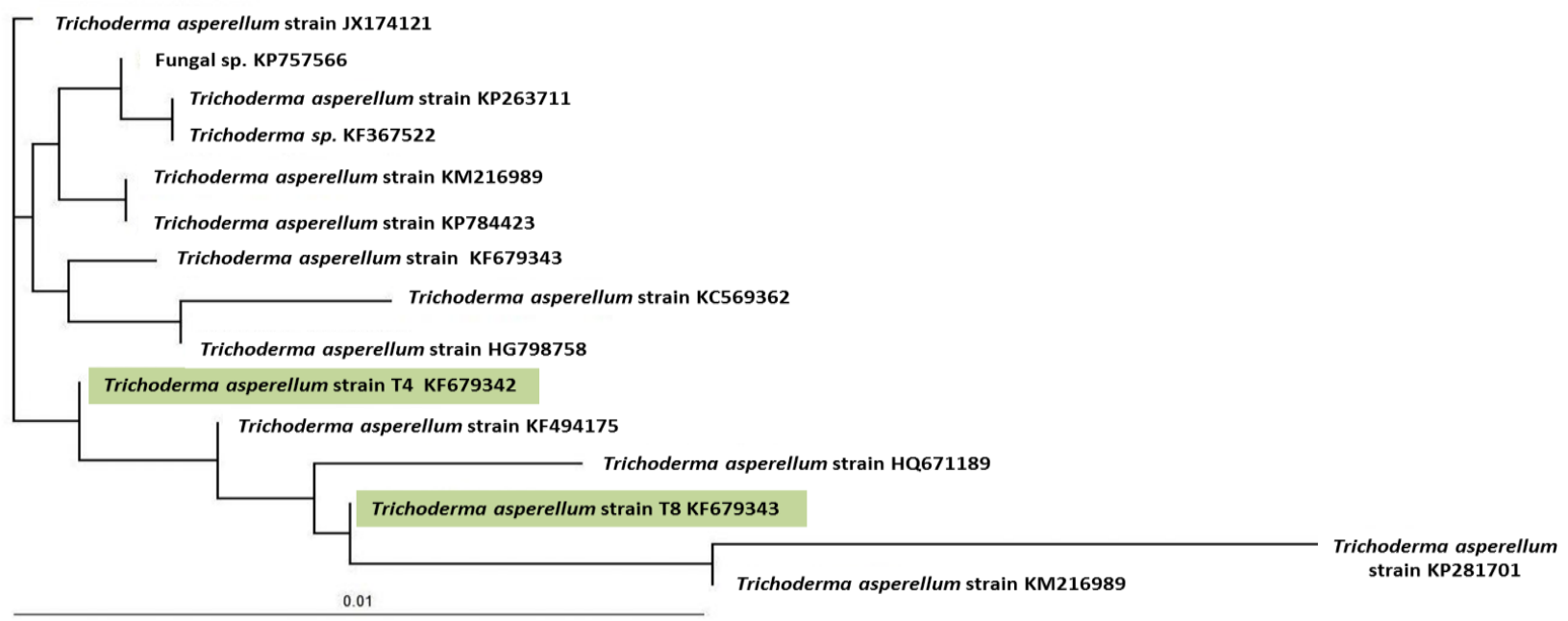

Reconstruction of phylogenetic trees is a statistical problem and a reconstructed tree is an estimate of a true tree with a given topology and given branch length. The correctness of this assessment should be statistically established. In preparation, phylogenetic analyses typically generate phylogenetic trees with correct parts and imprecise parts. Approaches using comparisons of base or codon arrangement have revealed that up to $17 \%$ of the genes of bacterial genomes maybe of alien origin, with only a few of them recognizable as mobile elements (Ochman et al., 2000). However, it was recently shown that other mechanisms may explain biases in nucleotide composition and that unforeseen sequence patterns may not be proofs of alien origin. Moreover, the several intrinsic approaches tend to give very diverse assessments of the pool of laterally transferred genes (Ragan, 2001).

Polymerase chain reaction (PCR) is an in situ DNA replication process that allows for the exponential amplification of target DNA in the presence of synthetic oligonucleotides primers and a thermostable DNA polymerase. A broad variety of diverse concentrations or units of DNA templates (5-25 ng), Taq DNA polymerase $(0.6-1.25 \mathrm{U})$, primers (0.11-
$10 \mu \mathrm{M})$, and temperature cycles $\left(45-95.8^{\circ} \mathrm{C}\right.$ and $30-40$ cycles) have been employed to detect or confirm bacteria isolated soil of a PCR reaction such as deoxyribonucleotide triphosphates (dNTPs), magnesium $\left(\mathrm{Mg}^{2+}\right)$ and buffer solutions have been used in different concentrations to increase detection limits. A PCR process may involve the use of one primer single or multiple primers to detect bacterial isolates (Adzitey et al., 2013). Comparison of the partial 16S rDNA sequences of isolates with GenBank database showed that they belongs ten isolates of $R$. solanacearum, three isolates of $P$. fluorescens and two isolates of $T$. asperellum lineages. Sequences from all isolates were completely or higher than $99 \%$ similar to other 16S rRNA sequences from GenBank database. The phylogenetic analysis based on the partial 16S rRNA gene sequencing $R$. solanacearum, P. fluorescens and T. asperellum (Figure 1-3).

In conclusion, conservation 16S rRNA region in the gene sequence could identify all isolates of isolated from rhizosphere soil samples successfully. This sequence can serve as a best molecular chronometer for identification of soil bacteria and fungi with no previous knowledge. Conservation is considered to gene a significant part of cell identification and this study, also, 
shows that partial sequencing can provide statistically valid measurements for evolutionary distances of both bacterial and fungal isolates.

\section{References}

Adzitey, F., Huda, N., Ali, G.R.R. 2013. Molecular techniques for detecting and typing of bacteria, advantages and application to food borne pathogens isolated from ducks. 3Biotech, 3(2): 97107.

Anderson, I.C., Cairney, W.G. 2004. Diversity and ecology of soil fungal communities: increased understanding through the application of molecular techniques. Environ Microbiol. 6: 769779.

Altschul, S. F., Suhai, S. 1997. Theoretical and computational methods in genome research. New York, 1-14.

Brown, J.R., Douady, C.J., Italia, M.J., Marshall, W.E., Stanhope, M.J. 2001.Universal trees based on large combined protein sequence data sets. Nat Genet. 28:281-285.

Ja, 1995. The RecA protein as a model molecule for molecular systematic studies of bacteria: comparison of trees of RecAs and $16 \mathrm{~S}$ rRNAs from the same species. J. Mol. Evol. 41:1105-1123.

King, E.O., Wood, M.K., Raney, D.E. 1954. Two Simple Media for the Demonstration of Pyocyanin and Fluorescein. J. Lab. Clinical Med.44, 301-307.
Maddison, W. 1997. Gene Trees in Species Trees. Systematic Biology 46:523-536.

Narasimha Murthy, K., Srinivas, C. 2012. In vitro screening of bioantagonistic agents and plant extracts to control bacterial wilt (R. solanacearum) of tomato (Lycopersicon esculentum). J. Agri. Technol. 8(3):999 -1015.

Ochman, H., Lawrence, J.G., Groisman, E.A. 2000. Lateral gene transfer and the nature of bacterial innovation. Nature. 405: 299 304.

Ragan, M.A. 2001. On surrogate methods for detecting lateral gene transfer. FEMS Microbiol.Lett.201:187-191.

Sacchi, C.T., Whitney, A.M., Reeves, M.W., Mayer, L.W., Popovic, T. 2002. Sequence diversity of Neisseria meningdidis 16S rRNA genes and use of $16 \mathrm{~S}$ rRNA gene sequencing as a molecular subtyping tool. J Clin Microbiol. 40:4520-4527.

Villa, J.E., Tsuchiya, K., Horita, M., Natural, M., Opina, N., Hyakumachi, M. 2005. Phylogenetic relationship of Ralstonia solanacearum species complex strain from Asia and other continents based on 16s rRNA, endoglucanase, and hrpB gene sequences. J. Gen. Plant Pathol. 71:39-46.

Woese, C.R., Fox, G.E. 1977. Phylogenetic structure of the prokaryotic domain: the primary kingdoms. Proc. Natl. Acad. Sci. USA. 74: 5088- 5090.

Wu, D., Hugenholtz, P., Mavromati, K., Pukall, R., Dalin, E., et al., 2009. A phylogenydriven genomic encyclopaedia of Bacteria and Archaea. Nature 462:1056-1060.

\section{How to cite this article:}

Soumya, K., K. Narasimha Murthy, C. Srinivas and Niranjana, S.R. 2019. Phylogenetic Diversity Analysis of Ralstonia solanacearum, Pseudomonas fluorescens and Trichoderma asperellum Isolated from Tomato Rhizosphere Soil in Karnataka. Int.J.Curr.Microbiol.App.Sci. 8(03): 381388. doi: https://doi.org/10.20546/ijcmas.2019.803.047 